\title{
Taste aversion and passive avoidance in rats with hippocampal lesions
}

\author{
CLAUDE R. MILLER, RALPH L. ELKINS, JAMES FRASER \\ I'eterans Administration Hospital, Augusta, Georgia 30904 \\ LELON J. PEACOCK \\ University of Georgia, Athens, Georgia 30601 \\ and \\ STEPHEN H. HOBBS \\ Augusta College, Augusta, Georgia 30904
}

\begin{abstract}
Rats with near total hippocampal lesions were compared with cortical and normal control animals on taste aversion and passive avoidance conditioning. While the initial magnitude of the taste aversion induced through illness was not significantly affected by hippocampal ablation, the aversion did extinguish more rapidly in experimental animals. Locomotor passive avoidance was significantly impaired by the lesion.
\end{abstract}

Not all stimuli impinging on an organism at the moment of a reinforcing event have an equal likelihood of entering into an association with the reinforcer. Instead, there seems to be a selection process for determining which stimulus from the total stimulus complex subsequently will come to serve as a cue for the reinforcing event. This stimulus selection appears to be determined to some extent by the nature of the reinforcer. For example, Garcia and Koelling (1966) found that audiovisual stimuli were readily associated with painful peripheral shock but not with gastrointestinal distress. Conversely, distinctive gustatory stimuli were readily associated with internal malaise but not with footshock. Garcia and Koelling (1966) suggested the existence of separate central mechanisms underlying different kinds of associations-one subserving associations between chemical stimuli (olfactory and gustatory) and the state of the internal environment, the other subserving associations between telereceptor stimuli (auditory and visual) and peripheral cutaneous stimulation.

If two distinct central mechanisms exist, it may be possible with the lesion technique to disrupt differentially the conditioning reinforced by induced illness or by electric shock (cf. Garcia, Hankins, \& Rusiniak, 1974). Evidence for such a separation already exists. Septal lesions appear to disrupt shock-reinforced, but not illness-reinforced, conditioning (Hobbs, Elkins, \& Peacock, 1974: McGowan, Garcia, Ervin, \& Schwartz, 1969: McGowan, Hankins, \& Garcia, 1972). In addition, McGowan et al. (1972) found that lesions of the ventral hippocampus impaired the development of response

Reprint requests should be addressed to Claude $R$. Miller, Department of Psychology, Georgia College, Milledgeville, Georgia 31061. suppression to an audiovisual stimulus which had been paired with electric shock, but not the conditioning of an aversion to a distinctive taste paired with induced illness. Dorsal hippocampal lesions had no significant effect on either conditioning process. However, some contradiction exists regarding the effects of hippocampal lesions. Best and Orr (1973) also studied dorsal and ventral hippocampal lesions and obtained results similar to those of McGowan et al. (1972) with respect to ventral lesions. However, unlike McGowan et al. (1972), Best and Orr's (1973) dorsal lesions disrupted conditioning in both paradigms. They attributed these dorsal effects to the fact that the dorsal lesions damaged the fimbria and thus were functionally larger than ventral lesions.

Previous studies of the effects of near total hippocampal ablation on the conditioning of taste aversions have resulted in either no effect (Murphy \& Brown, 1974) or mild disruption (Miller, Elkins, \& Peacock, 1971). The animals in the Miller et al. (1971) study had been extensively familiarized with the taste stimulus, possibly weakening the conditioning process (Elkins, 1973a: Farley, McLaurin, Scarborough, \& Rawlings, 1964). Neither study examined lesion effects on acquisition of a shock-motivated avoidance response.

The present study reexamined the effects of near total hippocampal lesions on a conditioned taste aversion employing a more powerful conditioning paradigm. In addition, it included a passive avoidance task based on shock.

\section{METHOD}

A total of 32 young adult male Sprague-Dawley rats, weighing 250-380 g, served as subjects. Twelve animals received large near total bilateral hippocampal lesions by means of aspiration while 
Table 1

Taste Aversion Measures for Each Subject in the Drug-Injected Groups

\begin{tabular}{rccc}
\hline Subject & $\begin{array}{c}\text { Day 1 } \\
\text { S Score }\end{array}$ & $\begin{array}{c}\text { Mean 5 Day } \\
\text { S Score }\end{array}$ & $\begin{array}{c}\text { Days to } \\
\text { Extinction }\end{array}$ \\
\hline 1 & \multicolumn{3}{c}{ Hippocampals } \\
2 & 3.01 & 3.14 & 29 \\
3 & 1.48 & 2.81 & 8 \\
4 & 3.49 & 17.26 & 53 \\
5 & 23.81 & 36.12 & 10 \\
6 & 95.75 & 95.79 & 2 \\
7 & 4.64 & 6.97 & 9 \\
& 3.95 & 5.60 & 12 \\
8 & & Cortical Controls & \\
9 & 1.45 & 2.04 & 52 \\
10 & 2.24 & 3.05 & 18 \\
11 & 1.97 & 2.48 & 55 \\
12 & 3.46 & 3.38 & 32 \\
& 13.58 & 8.35 & 42 \\
13 & & Normal Controls & \\
14 & 2.60 & 4.22 & 42 \\
15 & 1.45 & 1.95 & 54 \\
16 & 2.55 & 4.01 & 55 \\
17 & 1.73 & 2.51 & 33 \\
\hline
\end{tabular}

under Equithesin anesthesia $(3.75 \mathrm{cc} / \mathrm{kg})$. Ten animals received surgical control lesions in which the cerebral cortex overlying the hippocampus was removed. The remaining ten animals served as normal controls.

Following a two-week surgical recovery period, animals with hippocampal lesions were divided into two groups: a saline control group $(\mathrm{N}=5)$ and a cyclophosphamide (Cytoxan $R$ Mead-Johnson Laboratories) experimental group $(\mathrm{N}=7)$. The surgical and normal control groups also were divided into saline and drug groups with five animals in each condition. Animals were fluid deprived for $24 \mathrm{~h}$, and offered a $.05 \%$ sodium saccharin solution. The solution was available for a minimum of $10 \mathrm{~min}$ and for at least $5 \mathrm{~min}$ after the onset of ingestion. Four to six minutes following removal of the solution, each animal was injected intraperitoneally with either cyclophosphamide $(25 \mathrm{mg} / \mathrm{kg})$ or an equivalent volume of isotonic saline. The saccharin solution was reintroduced $5 \mathrm{~min}$ after the injection and was the only fluid available for the next $24 \mathrm{~h}$. At the end of that period, preference testing began by presenting each animal with two bottles, one containing the saccharin solution and the other tap water. Animals retained access to both bottles for the next 55 days except for brief periods each day when the bottles were weighed and refilled. Bottle positions were nonsystematically alternated to control for position preferences. Bottle-weight differences were used to determine the percentage of total daily fluid consumption accounted for by saccharin ingestion. This percentage was termed the $\mathrm{S}$ score.

Following fluid-preference measurement, animals were tested on a simple passive avoidance task in a two-way shuttlebox (Lafayette Model 85103). The grid floors of the shuttlebox were wired through a neon grid scrambler (Lafayette Model 58020) to a constant-current shocker (Lafayette Model 58006). The door separating the two compartments remained open throughout the testing period. Animals were placed in one chamber and allowed to cross to the other without experimenter intervention. However, when the animal returned to the start chamber, a $.5-\mathrm{mA}$ footshock was delivered until an escape response was made to the opposite compartment. The latency to reenter the start chamber following footshock was recorded. Animals which refused to reenter the start compartment within 5 min were given a maximum reentry latency $(300 \mathrm{sec})$ and the test was terminated.

Experimental and surgical control animals were sacrificed at the conclusion of behavioral testing and their brains were removed and embedded in celloidin. Sections were cut at 30 micrometers and every fifth section was mounted and stained with thionin. Lesion size was determined by an extension of the dot-grid method (Thomas \& Peacock, 1965).

\section{RESULTS}

Hippocampal lesions did not impair the acquisition of the taste aversion but did significantly reduce the time to extinction of the aversion. Acquisition of the passive avoidance response was significantly disrupted by the lesion.

In general, saline-injected animals showed a strong preference for the saccharin solution, while drug-injected animals exhibited a marked aversion to saccharin. The median S score for the first $24 \mathrm{~h}$ of preference testing for saline-injected animals with hippocampal lesions was 96.39. In the saline-injected surgical control and normal control groups, the median $\mathrm{S}$ scores for the first $24 \mathrm{~h}$ was 92.22 and 97.52 , respectively. This saccharin preference among saline-injected animals remained relatively constant throughout the 55-day testing period.

The data relevant to taste aversion conditioning among drug-injected animals are summarized in Table 1. An analysis of the $\mathrm{S}$ scores for the 1st day of extinction by means of the Kruskal-Wallis H test (Siegel, 1956) indicated that there were no significant differences in the initial aversion magnitude among the drug-injected groups $(\mathrm{H}=3.12, \mathrm{df}=2, \mathrm{p}>.10)$.

Since bottle positions were not changed during the first $24 \mathrm{~h}$ of testing, it was possible that the initial $\mathrm{S}$ scores reflected position preferences. However, an analysis of the mean $\mathrm{S}$ scores for the first 5 days of extinction, during which time daily bottle positions had been alternated, also indicated no significant differences among the drug-injected groups $(\mathrm{H}=4.56, \mathrm{df}=2$, $\mathrm{p}>.10)$.

There was a significant difference among the drug-injected groups on the rate of extinction of the taste aversion $(\mathrm{H}=6.45, \mathrm{df}=2, \mathrm{p}<.05)$. Extinction was defined as 2 consecutive days over which the mean saccharin consumption equalled or exceeded $50 \%$ of the total fluid intake. Between-group comparisons by means of the Mann-Whitney U test showed significantly more rapid extinction for experimental animals compared to surgical controls $(U=5, p<.05)$ and normal controls $(\mathrm{U}=6.5, \mathrm{p}<.05)$, but no significant differences between the two control groups. Inspection of the extinction data given in Table 1 generally supports the statistical conclusion. However, it must be noted that Subject 5 in the experimental group either did not develop an aversion or, if an aversion was formed, it extinguished during the 1st day of testing. Histological 
examination of the brain of this animal showed secondary, but unilateral, invasion of the caudate and amygdaloid nuclei. Because the damage was unilateral, and since there had been nothing unusual in the conditioning procedure for this animal, these data were not eliminated from the statistical analyses.

In the passive avoidance task, an analysis of the reentry latencies indicated a significant difference among the three groups $(\mathrm{H}=8.64, \mathrm{df}=2, \mathrm{p}<.05)$. Specifically, animals with hippocampal lesions exhibited significantly shorter reentry latencies than surgical controls $(U=18$, $p<.05)$ and normal controls $(U=25, p<.05)$. There was no significant difference between the two control groups. The median reentry latency for experimental animals was $21.0 \mathrm{sec}$, while the surgical and normal control animals showed median reentry latencies of $272.5 \mathrm{sec}$ and $154.0 \mathrm{sec}$, respectively. Among the 12 experimental animals, 2 did not reenter the compartment where they had been previously shocked, while 6 of 10 surgical controls and 4 of 10 normal controls refused to reenter that compartment within the 5-min time limit.

Since animals with hippocampal lesions were deficient in passive avoidance responding, correlations between reentry latency and measures of taste aversion conditioning were obtained to determine whether performances in the two tasks were related among the drug-injected animals. The coefficients were determined by means of the Spearman rank correlation procedure (Siegel, 1956). There was no significant relationship between reentry latency and 1 st-day $S$ scores $(+.18)$, between reentry latency and the mean $S$ score for the first 5 days of extinction testing $(+.03)$, or between reentry latency and days to extinction of the taste aversion $(-.44)$

Analysis of lesion extent indicated that the smallest lesion involved approximately $75 \%$ of the hippocampus (Animal 7 in Table 1) and the largest lesion was approximately $95 \%$ complete (Animal 4 in Table 1). Hippocampal tissue that remained intact generally was located along the dorsal midline or in the most ventral part of the hippocampus. The extent of neocortical damage in experimental animals tended to be somewhat greater than that of surgical controls but there was no apparent relationship between cortical damage and performance in the experimental tasks or between the extent of hippocampal damage and task performance. In general, the control and experimental lesions were quite comparable to those reported previously (Miller et al., 1971).

\section{DISCUSSION}

Damage to the hippocampus may result in a general nonspecific deficit in the ability to withhold a response (Douglas, 1967), or it may produce an inhibitory deficit specific to a particular associative process (McGowan et al., 1972). Both Best and Orr (1973) and McGowan et al. (1972) reported that ventral hippocampal lesions disrupted passive avoidance conditioning reinforced by electric shock, but not the acquisition of a bait-shyness response. While these findings appear to support the hypothesis that separate central mechanisms underlie these associative processes, they could also reflect procedural artifacts. For example, the motivational properties of electric shock and internal malaise could be quite different at the US intensities employed. An additional interpretive problem arises from Best and Orr's (1973) report that dorsal hippocampal lesions disrupted both bait-shyness and passive avoidance acquisition while McGowan et al. (1972) found no effects of dorsal lesions.

Results of the present experiment do not conclusively support either a nonspecific inhibitory deficit hypothesis or an association-specific inhibitory deficit hypothesis. Fluid preference testing on the first extinction day, or over the first 5 days of extinction, showed no significant aversion disruption in experimental animals. This finding, in conjunction with the lesion-induced disruption of shock-motivated passive avoidance, is similar to the reported effects of ventral hippocampal lesions (Best \& Orr, 1973; McGowan et al., 1972) and appears consistent with the hypothesis of separate central mechanisms underlying the different associative processes. However, the present experiment, unlike those of Best and Orr (1973) and McGowan et al. (1972), included extended extinction testing which indicated that conditioned subjects with hippocampal lesions lost the aversion more rapidly than control subjects. It could be argued that this accelerated extinction is indicative of bait-shyness disruption and a nonspecific deficit in response inhibition. The lesion-induced deficit may not have been observed initially because of strong conditioning procedures (cf. Elkins, 1973b). Miller et al. (1971), in fact, reported that hippocampal lesions disrupted a weak aversion established by pairing x-radiation with a familiar flavor. While Murphy and Brown (1974) recently found no effects of hippocampal lesions on extinction of a learned taste aversion, they employed a single stimulus procedure which may be less sensitive than the preference technique (Dragoin, McCleary, \& McCleary, 1971). Additional research will be required to determine if these or other factors can account for the conflicting results.

Another finding of the present study has relevance to the "general nonspecific" and the "specific associative mechanism" hypotheses of hippocampal functioning. McGowan et al. (1972) suggested that animals deficient in shock-motivated passive avoidance behavior tend to be more sensitive to oral-internal contingencies, as exemplified by flavor aversion behavior. Although animals in the present study given hippocampal lesions 
showed a marked deficit in passive avoidance behavior, none of the correlations between passive avoidance responding and taste aversion behavior approached statistical significance.

It can be concluded that hippocampal lesions, either near total or more discrete, may disrupt bait-shyness behavior under some conditioning methodologies and test procedures. The existence of separate associative processes in the brain remains a plausible hypothesis but one which fails to receive conclusive support from existing data on the hippocampus. As Best and Orr (1973) noted, such a hypothesis would be greatly strengthened by the demonstration of a lesion effect in which taste aversion conditioning is disrupted without a significant effect on conditioning reinforced by electric shock. Initial evidence for such an effect has been recently reported with lesions restricted to the anterior region of the olfactory bulbs (Elkins \& Hobbs, 1974).

\section{REFERENCES}

Best, P. J., \& Orr, J. Effects of hippocampal lesions on passive avoidance and taste aversion conditioning. Physiology \& Behavior, 1973, 10, 193-196.

Douglas, R. J. The hippocampus and behavior. Psychological Bulletin, 1967, 67, 416-442.

Dragoin, W., McCleary, G. E., \& McCleary, P. A comparison of two methods of measuring conditioned taste aversions. Behavior Research Methods \& Instrumentation, 1971, 3, 309-310.

Elkins, R. L. Attenuation of drug-induced bait shyness to a palatable solution as an increasing function of its availability prior to conditioning. Journal of Behavioral Biology, 1973a, 9, 221-226.

Elkins, R. L. Individual differences in bait shyness: Effects of drug dose and measurement technique. The Psychological Record, 1973b, 23, 349-358.

Elkins, R. L., \& Hobbs, S. H. Dissociation of shock-motivated compartment and drug-induced flavor aversions following selective olfactory system lesions. Presented at the Fourth Annual Meeting of Society for Neuroscience, St. Louis, Missouri, October 1974.

Farley, J. A., McLaurin, W. A., Scarborough, B. B., \& Rawlings, T. D. Preirradiation saccharin habituation: A factor in avoidance behaviox. Psychological Reports, 1964, 14, 491-496.

Garcia, J., Hankins, W. G., \& Rusiniak, K. W. Behavioral regulation of the milieu interne in man and rat. Science, 1974, $185,824-831$.

Garcia, J., \& Koelling, R. A. Relation of cue to consequence in avoidance learning. Psychonomic Science, 1966, 4, 123-124.

Hobbs, S. H., Elkins, R. L., \& Peacock, L. J. Taste-aversion conditioning in rats with septal lesions. Behavioral Biology, 1974, 11, 239-245.

McGowan, B. K., Garcia, J., Ervin, F. R., \& Schwartz, J. Effects of septal lesions on bait-shyness in the rat. Physiology \& Behavior, 1969, 4, 907-909.

McGowan, B. K., Hankins, W. G., \& Garcia, J. Limbic lesions and control of the internal and external environment. Behavioral Biology, 1972, 7, 841-852.

Miller, C. R., Elkins, R. L., \& Peacock, L. J. Disruption of radiation-induced preference shift by hippocampal lesions. Physiology \& Behavior, 1971, 6, 283-285.

Murphy, L. R., \& Brown, T. S. Hippocampal lesions and learned taste aversion. Physiological Psy chology, 1974, 2, 60-64.

Siegel, S. Nonparametric statistics for the behavioral sciences. New York: McGraw-Hill, 1956.

Thomas, R. K., \& Peacock, L. J. A method of measuring brain lesions. Psychonomic Science, 1965, 3, 184.

(Received for publication July 16, 1974; revision accepted October 8,1974 .)

\section{ERRATA}

DIVAC, I., WIKMARK, R. G. E., and GADE, A. Spontaneous alternation in rats with lesions in the frontal lobes: An extension of the frontal lobe syndrome. Phy siological Psychology, 1975, 3 (1), 3941. Page 41 , Column 1, a line should be inserted between the second and third lines from the bottom reading: "Damage to the septal nuclei or the hippocampus, two . "

On the same page, the fourth reference in Column 2 should read as follows: Divac, I. Frontal lobe system and spatial reversal in the rat. Neuropsychologia, 1971, 9, 175-183.

GULLIKSEN, HAROLD, \& VONEIDA, THEODORE. An attempt to obtain replicate learning curves in the split-brain cat. Physiological Psychology, 1975, 3 (1), 77-85. The first line of the first paragraph on page 33 should read as follows: "This study of learning curves in normal and split-brain cats investigated primarily the extent to which the course of learning using one hemisphere of a split-brain animal may be regarded as repeating or replicating the course of learning the same problem using the other hemisphere." 